\title{
The Association between Low Birth Weight and High Levels of Cholesterol Is Not Due to an Increased Cholesterol Synthesis or Absorption: Analysis in Twins
}

\author{
RICHARD G. IJZERMAN, COEN D.A. STEHOUWER, ECO J. DE GEUS, \\ MIRJAM M. VAN WEISSENBRUCH, HENRIETTE A. DELEMARRE-VAN DE WAAL, AND \\ DORRET I. BOOMSMA \\ Department of Internal Medicine and Institute for Cardiovascular Research [R.G.I., C.D.A.S.], \\ Department of Pediatrics, Institute for Endocrinology, Reproduction and Metabolism [R.G.I., M.M.W., \\ H.A.D.W.], VU University Medical Center; Department of Biological Psychology [E.J.G., D.I.B], Vrije \\ Universiteit, VU University Medical Center, Amsterdam, The Netherlands
}

\begin{abstract}
Low birth weight may be associated with high levels of
cholesterol in later life through genetic factors that affect both
birth weight and cholesterol metabolism. Alterations in choles-
terol synthesis and absorption may play an important role in this
association. We examined birth weight and plasma ratios of a
precursor of cholesterol, lathosterol (an estimate of cholesterol
synthesis), and plant sterols, campesterol and $\beta$-sitosterol (esti-
mates of cholesterol absorption), to cholesterol in 53 dizygotic
and $58 \mathrm{monozygotic}$ adolescent twin pairs. After adjustment for
current weight, birth weight was not associated with the ratios of
lathosterol, campesterol, and $\beta$-sitosterol either in the overall
sample $[+0.07 \mu \mathrm{mol} / \mathrm{mmol} / \mathrm{kg}(95 \%$ confidence interval: -0.11
to 0.25$), p=0.5 ;+0.02 \mu \mathrm{mol} / \mathrm{mmol} / \mathrm{kg}(-0.33$ to 0.37$), p=$
$0.9 ;$ and $-0.04 \mu \mathrm{mol} / \mathrm{mmol} / \mathrm{kg}(-0.23$ to 0.15$), p=0.8$, respec-
\end{abstract}
Low birth weight is associated with an increased risk of cardiovascular morbidity and mortality $(1,2)$. An atherogenic lipid profile may, in part, explain these associations (3-7). The association between birth weight and an atherogenic lipid profile has been attributed to a programmed response to intrauterine malnutrition that induces permanent changes in the structure and function of organs, which cause increased levels of cholesterol in later life (8). The alternative view is that genetic factors influencing both birth weight and lipid profile could explain the relationships between these two variables (9).

Studies in dizygotic and monozygotic (genetically identical) twin pairs offer a unique opportunity to investigate the influ-

Received January 25, 2002; accepted June 18, 2002.

Correspondence: Coen D. Stehouwer, Department of Medicine, VU University Medical Center, De Boelelaan 1117, PO Box 7057, 1007 MB Amsterdam, The Netherlands; e-mail: cda.stehouwer@vumc.nl.

Supported by The Netherlands Heart Foundation (grants 86.083 and 88.042).

DOI: 10.1203/01.PDR.0000036627.96386.3A tively] or in the intrapair analysis in dizygotic twins $[+0.27$ $\mu \mathrm{mol} / \mathrm{mmol} / \mathrm{kg}$ ( -0.28 to 0.82$), p=0.3 ;-0.03 \mu \mathrm{mol} / \mathrm{mmol} / \mathrm{kg}$ ( -1.07 to 1.01$), p=1.0$; and $+0.04 \mu \mathrm{mol} / \mathrm{mmol} / \mathrm{kg}(-0.56$ to $0.64), p=0.9$, respectively] or in the intrapair analysis in monozygotic twins $[+0.54 \mu \mathrm{mol} / \mathrm{mmol} / \mathrm{kg}(-0.09$ to 1.18$), p=$ $0.09 ;-0.60 \mu \mathrm{mol} / \mathrm{mmol} / \mathrm{kg}(-1.59$ to 0.39$), p=0.2$; and -0.43 $\mu \mathrm{mol} / \mathrm{mmol} / \mathrm{kg}$ ( -0.99 to 0.14$), p=0.14$, respectively]. Plasma levels of lathosterol, campesterol, and $\beta$-sitosterol, which are indicators of cholesterol synthesis and absorption, thus do not explain the association of low birth weight with high levels of total and LDL cholesterol. As an alternative hypothesis, we suggest that a decrease in cholesterol clearance may play an important role. (Pediatr Res 52: 868-872, 2002) ence of intrauterine and genetic factors. Differences within dizygotic twin pairs are a function of both genetic and nongenetic factors, whereas differences within monozygotic pairs are caused by nongenetic factors. In our cohort of adolescent twin pairs, we have previously shown that low birth weight was associated with high total and LDL cholesterol within dizygotic twin pairs, but with low total and LDL cholesterol within monozygotic twin pairs (10). These data suggest that the association of birth weight with total and LDL cholesterol is strongly influenced by the elimination of genetic factors. Therefore, these genetic factors play an important role in the association of low birth weight with elevated levels of total and LDL cholesterol (10).

The metabolic alterations in cholesterol metabolism that underlie these changes in plasma lipids are not known. Direct assessment of cholesterol synthesis is expensive, time consuming, and difficult in large-scale studies, but plasma ratios of lathosterol (a precursor of cholesterol), and campesterol and 
$\beta$-sitosterol (plant sterols) to cholesterol are indicators of whole-body cholesterol synthesis and absorption, respectively (11-16). In a study in children born preterm, Mortaz et al. (17) demonstrated that low birth weight was associated with an increase in cholesterol synthesis, as indicated by an increase in plasma lathosterol, and a compensatory decrease in cholesterol absorption, as indicated by a decrease in plasma campesterol. They interpreted this association as a consequence of intrauterine programming (17). However, both birth weight $(18,19)$ and indicators of cholesterol metabolism $(20,21)$ are influenced by genetic factors. Therefore, the association between them may also be explained by genetic influences.

To examine the association between birth weight and cholesterol metabolism and the possible influence of genetic factors, we investigated birth weight and markers of cholesterol synthesis and absorption in our sample of adolescent dizygotic and monozygotic twin pairs.

\section{METHODS}

Subjects. This study is part of a larger project in which cardiovascular risk factors were studied in 160 adolescent twin pairs and their parents (22-25). Addresses of twins living in Amsterdam and neighboring cities were obtained from city council population registries. Twins still living with their biologic parents were contacted by letter. A questionnaire was used to gather information on various factors, including the use of medication and smoking behavior. The maternal questionnaire included questions regarding birth weight and gestational age of their children. Opposite-sex dizygotic twin pairs were excluded because of the effects of sex differences within a pair on both birth weight and indicators of cholesterol metabolism. Subjects using oral contraceptives were also excluded for these analyses. None of the subjects used any other medication that may affect plasma concentrations of lathosterol, campesterol, and $\beta$-sitosterol. Thus, 53 dizygotic twin pairs (average age $17.0 \mathrm{y}$ ) and 58 monozygotic twin pairs (average age $16.0 \mathrm{y}$ ) were eligible for analysis. This study was approved by the institutional review board, and subjects gave their informed consent.

Measurements. Height and weight were measured in a standardized way. After acclimatization, EDTA blood was obtained between 0830 and $1030 \mathrm{~h}$ by venipuncture after overnight fasting. Plasma was separated from cells after centrifugation for $10 \mathrm{~min}$ at $3000 \mathrm{rpm}$. Concentrations of lathosterol, campesterol, and $\beta$-sitosterol were determined with gas chromatography on a $30-\mathrm{m} \times 0.25-\mathrm{mm}$ CP Sil $5 \mathrm{CB}$ column in a Chrompack model 438S gas chromatograph (Bergen op Zoom, The Netherlands), as described previously (25). Concentrations were expressed as micromole per liter. In addition, values were expressed as micromole per millimole of cholesterol, because the measurements of the sterols are influenced by plasma cholesterol levels (12-15). Cholesterol values of this sample $(10,24,25)$ were determined using enzymatic methods (CHOD-PAP kit number 236691, Roche Molecular Biochemicals, Mannheim, Germany). Although some studies investigating indicators of cholesterol metabolism have used gas chromatography to measure cholesterol, the use of enzymatic methods is in accordance with several studies that validated the use of lathosterol, campesterol, and $\beta$-sitosterol as indicators of cholesterol metabolism (11-13), and with the study of Mortaz et al. (17) in which an association between birth weight and indicators of cholesterol metabolism was found in preterm singletons.

Data analysis. In the overall sample, linear regression analysis was used to investigate the influence of birth weight on indicators of cholesterol metabolism after adjustment for age and sex, and after additional adjustment for current weight. An interaction analysis was performed to investigate whether zygosity or current weight influenced these associations. Intrapair analyses were performed to investigate the influence of intrauterine and genetic factors $(10,23,26-31)$. As a first intrapair analysis, the paired $t$ test was used to compare twins with the lowest birth weight from each pair with their co-twins with the highest birth weight. For this analysis, two dizygotic and two monozygotic twin pairs had to be excluded, because the birth weight of the twins within a pair was equal. In addition, linear regression analysis was used to analyze whether intrapair differences in birth weight influenced intrapair differences in indicators of cholesterol metabolism before and after adjustment for differences in current weight (including the four twin pairs in which the birth weight of the twins within a pair was equal). Intrapair differences in birth weight were calculated by randomly subtracting the co-twin with the lowest birth weight from the co-twin with the highest birth weight or vice vera (32). Interaction analysis was performed to investigate whether zygosity or differences in current weight influenced the associations between intrapair differences in birth weight and indicators of cholesterol metabolism. A two-tailed $p$ value $<0.05$ was considered significant. All analyses were performed on a personal computer using the statistical software package SPSS version 9.0 (SPSS Inc., Chicago, IL, U.S.A.).

\section{RESULTS}

Lathosterol, campesterol, and $\beta$-sitosterol (whether expressed as concentration or as ratio to cholesterol) were not

Table 1. Associations between birth weight and indicators of cholesterol metabolism in the overall sample of twins

\begin{tabular}{lrl}
\hline & $\beta(95 \% \mathrm{CI}) \dagger$ & $p$ value \\
\hline Adjusted for age and sex & $0.17(-0.55$ to 0.89$)$ & 0.6 \\
Lathosterol $(\mu \mathrm{mol} / \mathrm{L})$ & $-0.39(-1.75$ to 0.97$)$ & 0.6 \\
Campesterol $(\mu \mathrm{mol} / \mathrm{L})$ & $-0.40(-1.15$ to 0.35$)$ & 0.3 \\
$\beta$-Sitosterol $(\mu \mathrm{mol} / \mathrm{L})$ & $0.11(-0.06$ to 0.29$)$ & 0.2 \\
Lathosterol ratio $(\mu \mathrm{mol} / \mathrm{mmol})^{*}$ & $-0.04(-0.38$ to 0.30$)$ & 0.8 \\
Campesterol ratio $(\mu \mathrm{mol} / \mathrm{mmol})^{*}$ & $-0.06(-0.24$ to 0.13$)$ & 0.5 \\
$\beta$-Sitosterol ratio $(\mu \mathrm{mol} / \mathrm{mmol})^{*}$ & & \\
Adjusted for age, sex and current weight & & \\
Lathosterol $(\mu \mathrm{mol} / \mathrm{L})$ & $-0.02(-0.72$ to 0.76$)$ & 1.0 \\
Campesterol $(\mu \mathrm{mol} / \mathrm{L})$ & $-0.29(-1.50$ to 1.28$)$ & 0.9 \\
$\beta$-Sitosterol $(\mu \mathrm{mol} / \mathrm{L})$ & $0.07(-0.11$ to 0.25$)$ & 0.6 \\
Lathosterol ratio $(\mu \mathrm{mol} / \mathrm{mmol})^{*}$ & $0.02(-0.33$ to 0.37$)$ & 0.9 \\
Campesterol ratio $(\mu \mathrm{mol} / \mathrm{mmol})^{*}$ & $-0.04(-0.23$ to 0.15$)$ & 0.8 \\
$\beta$-Sitosterol ratio $(\mu \mathrm{mol} / \mathrm{mmol})^{*}$ &
\end{tabular}

CI, confidence interval.

* Indicates $\mu \mathrm{mol} / \mathrm{mmol}$ of total cholesterol.

$\dagger \beta(95 \% \mathrm{CI})$ per kilogram birth weight. 
related to birth weight in the overall sample (Table 1, upper panel). The results were similar after additional adjustment for current weight (Table 1, lower panel). Interaction analysis indicated no effect modification by zygosity or current weight (data not shown).

Comparison between co-twins with the lowest and co-twins with the highest birth weight. Birth weight and gestational age were similar in dizygotic and monozygotic twins (Table 2). The differences in birth weight between the co-twins with the lowest birth weight and those with the highest birth weight from each pair were similar for dizygotic and monozygotic twin pairs (380 g and $306 \mathrm{~g}$, respectively, $p=0.2$; Table 2). Lathosterol, campesterol, and $\beta$-sitosterol (whether expressed as concentration or as ratio to cholesterol) were similar in the twins with the lowest and the highest birth weight in both dizygotic and monozygotic twins.

Associations between intrapair differences in birth weight and indicators of cholesterol metabolism. To further explore the relation between birth weight and indicators of cholesterol metabolism, we determined the associations between intrapair differences in birth weight and differences in lathosterol, campesterol, and $\beta$-sitosterol. Intrapair differences in the indicators of cholesterol metabolism (whether expressed as concentration or as ratio to cholesterol) were not related to intrapair differences in birth weight in the dizygotic twin pairs either before or after adjustment for differences in current weight (Table 3). In the unadjusted intrapair analysis in monozygotic twins, low birth weight was associated with low concentrations of lathosterol and high concentrations of campesterol and $\beta$-sitosterol. However, only the association with lathosterol was statistically significant. After controlling for cholesterol levels by using the ratio of lathosterol to cholesterol, the intrapair association of birth weight with lathosterol was smaller. After additional adjustment for differences in current weight, the association was of borderline significance (Table 3). Interaction analysis indicated that the associations between intrapair differences in birth weight and differences in lathosterol, campesterol, and $\beta$-sitosterol (whether expressed as concentration or as ratio to cholesterol) were not significantly influenced by zygosity or differences in current weight $(p>0.2)$.

Additional analyses. After restricting the analyses to subjects born after a gestational age $<37 \mathrm{wk}$, low birth weight was associated with a decreased ratio of lathosterol to cholesterol [ $+0.30 \mu \mathrm{mol} / \mathrm{mmol} / \mathrm{kg}$ (95\% confidence interval: $0.04-0.56)$, $p=0.03]$. The results of the intrapair analyses in this subgroup, however, were similar compared with the results of the intrapair analyses in the total group. In these subjects, birth weight was not associated with campesterol and $\beta$-sitosterol. Adjustment for gestational age or differences in smoking did not change the results (data not shown). The results were also similar if the associations were adjusted for differences in current body mass index instead of current weight.

\section{DISCUSSION}

We studied 53 dizygotic and 58 monozygotic adolescent twin pairs. We have previously demonstrated in this sample that low birth weight was associated with high total and LDL cholesterol within dizygotic twin pairs, but with low total and LDL cholesterol within monozygotic twin pairs (10). In addition, indicators of cholesterol metabolism (i.e. lathosterol, campesterol, and $\beta$-sitosterol) were related to cholesterol and current weight in this sample (25). Therefore, this sample allowed us to investigate whether the association between birth weight and cholesterol is influenced by cholesterol synthesis or absorption, and the possible influence of genetic factors. We could not demonstrate an association of birth weight with indicators of cholesterol synthesis and absorption either in the overall sample or in the intrapair analysis in dizygotic and monozygotic twin pairs.

Several studies have found an association of low birth weight with high total and LDL cholesterol in singletons (3-5) and we have previously reported this association in the overall

Table 2. Clinical characteristics of the co-twins with the lowest and the highest birth weight in dizygotic and monozygotic twin pairs

\begin{tabular}{|c|c|c|c|c|c|c|}
\hline & \multicolumn{3}{|c|}{ Dizygotic twin pairs } & \multicolumn{3}{|c|}{ Monozygotic twin pairs } \\
\hline Birth weight (g) & $2246 \pm 493$ & $2626 \pm 558$ & $<0.001$ & $2319 \pm 529$ & $2625 \pm 485$ & $<0.001$ \\
\hline Gestational age (wk) & $36 \pm 8.4$ & $36 \pm 8.4$ & - & $37 \pm 2.8$ & $37 \pm 2.8$ & - \\
\hline No. (male/female) & $51(30 / 21)$ & $51(30 / 21)$ & - & $56(29 / 27)$ & $56(29 / 27)$ & - \\
\hline Current BMI $\left(\mathrm{kg} / \mathrm{m}^{2}\right)$ & $20.0 \pm 1.9$ & $20.3 \pm 2.2$ & 0.5 & $19.5 \pm 2.3$ & $19.7 \pm 2.3$ & 0.2 \\
\hline Smoking & 7 & 9 & - & 4 & 4 & - \\
\hline Total cholesterol $(\mathrm{mmol} / \mathrm{L})$ & $4.15 \pm 0.71$ & $3.99 \pm 0.62$ & 0.1 & $4.23 \pm 0.80$ & $4.32 \pm 0.79$ & 0.1 \\
\hline Lathosterol $(\mu \mathrm{mol} / \mathrm{L})$ & $6.27 \pm 2.80$ & $6.43 \pm 2.58$ & 0.8 & $6.37 \pm 2.13$ & $7.24 \pm 3.21$ & 0.10 \\
\hline Campesterol $(\mu \mathrm{mol} / \mathrm{L})$ & $12.76 \pm 5.95$ & $12.51 \pm 5.75$ & 0.8 & $12.42 \pm 4.48$ & $11.80 \pm 4.78$ & 0.4 \\
\hline$\beta$-Sitosterol $(\mu \mathrm{mol} / \mathrm{L})$ & $7.10 \pm 3.56$ & $6.94 \pm 2.93$ & 0.8 & $6.96 \pm 2.68$ & $6.36 \pm 2.33$ & 0.2 \\
\hline
\end{tabular}

Mean \pm SD. BMI, body mass index. The association between birth weight and total cholesterol has been investigated previously 10 .

* Expressed as $\mu \mathrm{mol} / \mathrm{mmol}$ of total cholesterol. 
Table 3. Associations between intrapair differences in birth weight and differences in indicators of cholesterol metabolism in dizygotic and monozygotic twin pairs

\begin{tabular}{|c|c|c|c|c|}
\hline & \multicolumn{2}{|c|}{ Dizygotic twin pairs } & \multicolumn{2}{|c|}{ Monozygotic twin pairs } \\
\hline & $\beta(95 \% \mathrm{CI}) \dagger$ & $p$ Value & $\beta(95 \% \mathrm{CI}) \dagger$ & $p$ Value \\
\hline \multicolumn{5}{|l|}{ Unadjusted } \\
\hline Lathosterol ( $\mu \mathrm{mol} / \mathrm{L})$ & $0.56(-1.60$ to 2.73$)$ & 0.6 & $3.55(0.91$ to 6.18$)$ & 0.01 \\
\hline Campesterol $(\mu \mathrm{mol} / \mathrm{L})$ & $-2.3 \quad(-5.98$ to 1.38$)$ & 0.2 & $-0.49(-4.64$ to 3.67$)$ & 0.8 \\
\hline$\beta$-Sitosterol $(\mu \mathrm{mol} / \mathrm{L})$ & $-1.24(-3.41$ to 0.92$)$ & 0.3 & $-1.10(-3.37$ to 1.17$)$ & 0.3 \\
\hline Lathosterol ratio $(\mu \mathrm{mol} / \mathrm{mmol})^{*}$ & $0.40(-0.11$ to 0.91$)$ & 0.12 & $0.75(0.10$ to 1.40$)$ & 0.02 \\
\hline Campesterol ratio $(\mu \mathrm{mol} / \mathrm{mmol})^{*}$ & $-0.35(-1.31$ to 0.61$)$ & 0.5 & $-0.24(-1.26$ to 0.79$)$ & 0.6 \\
\hline$\beta$-Sitosterol ratio $(\mu \mathrm{mol} / \mathrm{mmol}) *$ & $-0.19(-0.76$ to 0.37$)$ & 0.5 & $-0.33(-0.88$ to 0.23$)$ & 0.2 \\
\hline \multicolumn{5}{|c|}{ Adjusted for differences in current weight } \\
\hline Lathosterol $(\mu \mathrm{mol} / \mathrm{L})$ & $-0.03(-2.39$ to 2.32$)$ & 1.0 & $2.75(0.15$ to 5.34$)$ & 0.04 \\
\hline Campesterol $(\mu \mathrm{mol} / \mathrm{L})$ & $-1.04(-4.99$ to 2.92$)$ & 0.6 & $-1.91(-5.93$ to 2.11$)$ & 0.3 \\
\hline$\beta$-Sitosterol $(\mu \mathrm{mol} / \mathrm{L})$ & $-0.27(-2.56$ to 2.02$)$ & 0.8 & $-1.43(-3.77$ to 0.90$)$ & 0.2 \\
\hline Lathosterol ratio $(\mu \mathrm{mol} / \mathrm{mmol})^{*}$ & $0.27(-0.28$ to 0.82$)$ & 0.3 & $0.54(-0.09$ to 1.18$)$ & 0.09 \\
\hline Campesterol ratio $(\mu \mathrm{mol} / \mathrm{mmol})^{*}$ & $-0.03(-1.07$ to 1.01$)$ & 1.0 & $-0.60(-1.59$ to 0.39$)$ & 0.2 \\
\hline$\beta$-Sitosterol ratio $(\mu \mathrm{mol} / \mathrm{mmol})^{*}$ & $0.04(-0.56$ to 0.64$)$ & 0.9 & $-0.43(-0.99$ to 0.14$)$ & 0.14 \\
\hline
\end{tabular}

CI, confidence interval.

* Indicates $\mu \mathrm{mol} / \mathrm{mmol}$ of total cholesterol.

$\dagger \beta(95 \% \mathrm{CI})$ per kilogram birth weight.

sample of twins and in the intrapair analysis in dizygotic twin pairs (10). In the present study, we could not demonstrate an association between low birth weight and an increased cholesterol synthesis or absorption, as indicated by elevated plasma levels of lathosterol, campesterol, and $\beta$-sitosterol. We cannot exclude the possibility that low birth weight may be associated with other indicators of cholesterol metabolism, such as squalene, methyl sterols, and cholestanol (33), or with direct measurements of cholesterol metabolism using radioactive isotope techniques (33). However, many studies have shown that plasma ratios of lathosterol, campesterol, and $\beta$-sitosterol to cholesterol are useful indicators of cholesterol metabolism (12-16). Therefore, we propose that the association between low birth weight and high levels of total and LDL cholesterol may be due to a decreased cholesterol clearance. This could be investigated by studying the in vivo kinetics of apolipoprotein B containing lipoproteins using a stable isotope approach (34).

The intrapair association between differences in birth weight and differences in lathosterol in monozygotic twins may suggest an explanation for our previous finding of an association of low birth weight with low total and LDL cholesterol after the elimination of genetic influences (10). However, it should be noted that this association was only of borderline significance. Interestingly, the finding of an association of low birth weight with low cholesterol levels is in line with a study in rats that demonstrated lower plasma cholesterol concentrations after maternal undernutrition (35).

Our results differ from the results from Mortaz et al. (17). They demonstrated, in preterm infants, that low birth weight was associated with an increase in cholesterol synthesis, as indicated by an increase in plasma lathosterol, and a compensatory decrease in cholesterol absorption, as indicated by a decrease in plasma campesterol (17). In our study, we could not detect these associations. In the total group of subjects, birth weight was not associated with cholesterol synthesis or absorption. After restricting the analyses to subjects born after a gestational age $<37 \mathrm{wk}$, low birth weight was associated with a decreased, not an increased, ratio of lathosterol to cholesterol. However, the results of Mortaz et al. may differ from ours for several reasons. First, the subjects in the study of Mortaz et al. were born very prematurely (average gestational age $31.1 \mathrm{wk}$ ), whereas our subjects were born after $36.3 \mathrm{wk}$, which is considered the term period for a twin pregnancy. Second, subjects in the study of Mortaz et al. were younger than our twin subjects (11.2 y versus $16.5 \mathrm{y}$ ).

It has been suggested that intrauterine growth in twins is not comparable to intrauterine growth in singletons. However, birth weight in twins has been associated with many variables that have been related to birth weight in singletons, such as blood pressure $(23,26)$, diabetes $(28,29)$, myocardial infarction (30), and height (31). These studies suggest that differences in birth weight in twins can be used as a model for differences in birth weight in singletons.

In summary, we found no evidence that plasma levels of lathosterol, campesterol, and $\beta$-sitosterol, which are indicators of cholesterol synthesis and absorption, can explain the association of low birth weight with high levels of total and LDL cholesterol. As an alternative hypothesis, we suggest that the association between low birth weight and high levels of total and LDL cholesterol is due to a decreased cholesterol clearance.

\section{REFERENCES}

1. Frankel S, Elwood P, Sweetnam P, Yarnell J, Smith GD 1996 Birthweight, body-mass index in middle age, and incident coronary heart disease. Lancet 348:1478-1480

2. Rich-Edwards JW, Stampfer MJ, Manson JE, Rosner B, Hankinson SE, Colditz GA, Willett WC, Hennekens CH 1997 Birth weight and risk of cardiovascular disease in a cohort of women followed up since 1976. BMJ 315:396-400

3. Bavdekar A, Yajnik CS, Fall CH, Bapat S, Pandit AN, Deshpande V, Bhave S, Kellingray SD, Joglekar C 1999 Insulin resistance syndrome in 8-year-old Indian children: small at birth, big at 8 years, or both? Diabetes 48:2422-2429

4. Kawabe H, Shibata H, Hirose H, Tsujioka M, Saito I, Saruta T 1999 Sexual differences in relationships between birth weight or current body weight and blood pressure or cholesterol in young Japanese students. Hypertens Res 22:169-172

5. Barker DJ, Martyn CN, Osmond C, Hales CN, Fall CH 1993 Growth in utero and serum cholesterol concentrations in adult life. BMJ 307:1524-1527

6. Fall CH, Barker DJ, Osmond C, Winter PD, Clark PM, Hales CN 1992 Relation of infant feeding to adult serum cholesterol concentration and death from ischaemic heart disease. BMJ 304:801-805 
7. Fall CH, Osmond C, Barker DJ, Clark PM, Hales CN, Stirling Y, Meade TW 1995 Fetal and infant growth and cardiovascular risk factors in women. BMJ 310:428-432

8. Barker DJ 1998 Mothers, Babies and Health in Later Life, 2nd Ed. Churchill Livingstone, Edinburgh

9. Hattersley AT, Tooke JE 1999 The fetal insulin hypothesis: an alternative explanation of the association of low birthweight with diabetes and vascular disease. Lancet 353:1789-1792

10. Ijzerman RG, Stehouwer CD, van Weissenbruch MM, de Geus EJ, Boomsma DI 2001 Evidence for genetic factors explaining the association between birth weight and LDL cholesterol, and possible intrauterine factors influencing the association between birth weight and HDL cholesterol: analysis in twins. J Clin Endocrinol Metab 86:5479-5484

11. Miettinen TA, Tilvis RS, Kesaniemi YA 1989 Serum cholestanol and plant stero levels in relation to cholesterol metabolism in middle-aged men. Metabolism 38:136140

12. Kempen HJ, Glatz JF, Gevers Leuven JA, van der Voort HA, Katan MB 1988 Serum lathosterol concentration is an indicator of whole-body cholesterol synthesis in humans. J Lipid Res 29:1149-1155

13. Miettinen TA, Tilvis RS, Kesaniemi YA 1990 Serum plant sterols and cholesterol precursors reflect cholesterol absorption and synthesis in volunteers of a randomly selected male population. Am J Epidemiol 131:20-31

14. Tilvis RS, Miettinen TA 1986 Serum plant sterols and their relation to cholestero absorption. Am J Clin Nutr 43:92-97

15. Bjorkhem I, Miettinen T, Reihner E, Ewerth S, Angelin B, Einarsson K 1987 Correlation between serum levels of some cholesterol precursors and activity of HMG-CoA reductase in human liver. J Lipid Res 28:1137-1143

16. Tammi A, Ronnemaa T, Rask-Nissila L, Miettinen TA, Gylling H, Valsta L, Viikar J, Valimaki I, Simell O 2001 Apolipoprotein E phenotype regulates cholesterol absorption in healthy 13-month-old children-The STRIP Study. Pediatr Res 50:688-691

17. Mortaz M, Fewtrell MS, Cole TJ, Lucas A 2001 Birth weight, subsequent growth, and cholesterol metabolism in children 8-12 years old born preterm. Arch Dis Child $84: 212-217$

18. van Baal CG, Boomsma DI 1998 Etiology of individual differences in birth weight of twins as a function of maternal smoking during pregnancy. Twin Res 1:123-130

19. Magnus $P 1984$ Further evidence for a significant effect of fetal genes on variation in birth weight. Clin Genet 26:289-296

20. Kesaniemi YA, Koskenvuo M, Vuoristo M, Miettinen TA 1989 Biliary lipid composition in monozygotic and dizygotic pairs of twins. Gut 30:1750-1756

21. Boomsma DI 1992 Quantative genetic analysis of cardiovascular risk factors in twins and their parents. PhD thesis, Vrije Universiteit, Amsterdam
22. Boomsma DI, Kaptein A, Kempen HJ, Gevers LJ, Princen HM 1993 Lipoprotein(a) relation to other risk factors and genetic heritability. Results from a Dutch parent-twin study. Atherosclerosis 99:23-33

23. Ijzerman RG, Stehouwer CD, Boomsma DI 2000 Evidence for genetic factors explaining the birth weight-blood pressure relation: analysis in twins. Hypertension 36:1008-1012

24. Boomsma DI, Kempen HJ, Gevers LJ, Havekes L, de Knijff P, Frants RR 1996 Genetic analysis of sex and generation differences in plasma lipid, lipoprotein, and apolipoprotein levels in adolescent twins and their parents. Genet Epidemiol 13:49-60

25. Kempen HJ, de Knijff P, Boomsma DI, van der Voort HA, Gevers Leuven JA, Havekes L 1991 Plasma levels of lathosterol and phytosterols in relation to age, sex, anthropometric parameters, plasma lipids, and apolipoprotein E phenotype, in 160 Dutch families. Metabolism 40:604-611

26. Dwyer T, Blizzard L, Morley R, Ponsonby AL 1999 Within pair association between birth weight and blood pressure at age 8 in twins from a cohort study. BMJ 319:1325-1329

27. Poulter NR, Chang CL, MacGregor AJ, Snieder H, Spector TD 1999 Association between birth weight and adult blood pressure in twins: historical cohort study. BMJ 319:1330-1333

28. Poulsen P, Vaag AA, Kyvik KO, Moller JD, Beck-Nielsen H 1997 Low birth weight is associated with NIDDM in discordant monozygotic and dizygotic twin pairs. Diabetologia 40:439-446

29. Bo S, Cavallo-Perin P, Scaglione L, Ciccone G, Pagano G 2000 Low birthweight and metabolic abnormalities in twins with increased susceptibility to Type 2 diabetes mellitus. Diabet Med 17:365-370

30. Hubinette A, Cnattingius S, Ekbom A, de Faire U, Kramer M, Lichtenstein P 2001 Birthweight, early environment, and genetics: a study of twins discordant for acute myocardial infarction. Lancet 357:1997-2001

31. Allison DB, Paultre F, Heymsfield SB, Pi-Sunyer FX 1995 Is the intra-uterine period really a critical period for the development of adiposity? Int J Obes Relat Metab Disord 19:397-402

32. Bring J, Wernroth L 1999 Inefficient analysis of twin data: is there an association between diabetes and birth weight? Diabetologia 42:898-899

33. Crouse JR, Grundy SM 1978 Evaluation of a continuous isotope feeding method for measurement of cholesterol absorption in man. J Lipid Res 19:967-971

34. Pietzsch J, Wiedemann B, Julius U, Nitzsche S, Gehrisch S, Bergmann S, Leonhard W, Jaross W, Hanefeld M 1996 Increased clearance of low density lipoprotein precursors in patients with heterozygous familial defective apolipoprotein B-100: a stable isotope approach. J Lipid Res 37:2074-2087

35. Lucas A, Baker BA, Desai M, Hales CN 1996 Nutrition in pregnant or lactating rats programs lipid metabolism in the offspring. Br J Nutr 76:605-612 